\title{
Imaginative Interfaces of Malaysian's Traditional Games as an Indoor Activity
}

\author{
Norfadilah Kamaruddin 1, Haryati Kamaruddin 1, Noor Shamsarini Md Isa 1, Hafizah Rosli 2 \\ 1 Universiti Teknologi MARA, Faculty Art and Design, Shah Alam, 40450, Malaysia \\ 2 Universiti Teknologi MARA, Faculty of Film, Teater and Animation, Puncak Perdana, 42300, Malaysia \\ norfadilah@uitm.edu.my, haryati.hk@gmail.com, shamsarini@uitm.edu.my, hafizahrosli@ uitm.edu.my \\ Tel: 0123486324
}

\begin{abstract}
Smartphones and video games are the most common activity among children to pass the time. Nevertheless, traditional games are still necessities relevant within today's generation. Ketingting is a traditional game that is entertaining and beneficial for the players' mental and physical development. As most people spend most of their time at home during this pandemic, this study proposes an expanding look and feels of traditional Malaysian games based on new interface design and material. This new attractive approach will encourage children to play traditional games as an indoor activity.
\end{abstract}

Keywords: Ketingting; Traditional Game; Heritage; Culture Preservation

eISSN: 2398-4287 @ 2021. The Authors. Published for AMER ABRA cE-Bs by E-International Publishing House, Ltd., UK. This is an open-access article under the CC BYNC-ND license (http://creativecommons.org/licenses/by-nc-nd/4.0/). Peer-review under responsibility of AMER (Association of Malaysian Environment-Behaviour Researchers), ABRA (Association of Behavioural Researchers on Asians) and CE-Bs (Centre for Environment-Behaviour Studies), Faculty of Architecture, Planning \& Surveying, Universiti Teknologi MARA, Malaysia.

DOI: https://doi.org/10.21834/ebpj.v6iSl6.3050

\subsection{Introduction}

Playing is a way for children to demonstrate their extraordinary abilities for exploration, imagination, and decision-making. Traditionally, children would congregate each evening on a field, playground, or even in their backyard with other friends to pass the time. However, nowadays, everything is changing with various gadgets and online games. As a result, most children prefer to play alone, and this situation is exacerbated when a pandemic Covid-19 hits the world and pressures many parents to prohibit their children from going out and playing indoors due to safety and health factors.

Regardless of the changing dimensions within society's civilization, the development of information technology has taken over children's lifestyles and distanced them from transmissible culture and heritage. Heritage moreover can improve the younger generation towards understanding their culture and instill the spirit of belonging, including traditional games (Abdullah, 2018). Nevertheless, traditional games can be modernized through innovation spirit with appropriate elements. Further, it can be played with family members as an indoor activity in their home area. According to (Sulistyaningtyas \& Fauziah, 2019), a traditional game may offer many benefits in all aspects of early childhood development, including physical-motor, social-emotional, moral, cognitive, and speech development. It also has human and cultural values and beliefs that formed the basis for motor skills development where can assist children in developing an understanding of the world. Thus the children will feel completely comfortable and happy while playing the games (Sulistyaningtyas \& Fauziah, 2019). It has been reported that traditional games are categorized as part of recreational activity (Mohd. Salleh Aman, 2006; Putra et al., 2014). According to (Putra et al., 2014), the older generation across various ages, races, and cultures, particularly farmers, was contesting physical activities through traditional activities games after harvest season. Additionally, the traditional games are performed not only for increasing our body strength and posture balance (Adnan et al., 2020; Sahay, 2013) but also involves a lot of movements, which are mostly related

eISSN: 2398-4287 C 2021. The Authors. Published for AMER ABRA cE-Bs by E-International Publishing House, Ltd., UK. This is an open-access article under the CC BYNC ND license (http://creatiecommons.org/licenses/by-nc-nd/4.0/). Peer-review under responsibility of AMER (Association of Malaysian Environment-Behaviour Researchers), ABRA (Association of Behavioural Researchers on Asians) and cE-Bs (Centre for Environment-Behaviour Studies), Faculty of Architecture, Planning \& Surveying, Universiti Teknologi MARA, Malaysia.

DOI: https://doi.org/10.21834/ebpj.v6iSI6.3050 
to the stimulations of motor fitness components (Sahay, 2013). Hence, playing a traditional game allows us to assimilate and integrate our life experiences.

Ketingting, congkak, sepak bulu ayam, tok harimau, gasing, batu seremban, and galah panjang are just a few of the numerous traditional games played by Malaysia's elderly. All of those traditional games are commonly played with materials that can be found in the surrounding area. For example, the Ketingting game, which uses only stone, requires players to be available to respond, have quick reaction times, and maintain balance while moving or jumping into each compartment. Many studies have discovered that most of these traditional games have become unpopular and less engaging among younger generations in recent years. The rapid advancement of technology has resulted in young children becoming more interested in watching television, playing electronic games, and participating in online games.

This research aims to propose a new interface design for the Ketingting games that are visually appealing and encourages children to participate in traditional games as an indoor activity. The findings of this study are highly beneficial for children who are learning to appreciate traditional games and for their parents. Furthermore, if it is played as an indoor activity, it will indirectly ensure the continuation of the traditional games of our forefathers and foremothers.

\subsection{A Malaysian Traditional Games}

Traditional Malaysian games are frequently associated with culture and involve physical activity, while others require the use of critical thinking and strategy. On the other hand, the traditional Malaysian games require little in the way of equipment and follow a straightforward set of rules. Traditional Malaysian children's games such as Congkak (filling the wooden board), Batu Seremban (tossing the stones), Tarik Upih, Ketingting, and Gasing (Table 1), which have been around for a long time, are examples of this rich cultural heritage that encourages physical activity. However, as a result of digital technologies and the impact of globalization, these traditional Malaysian children's games were gradually becoming extinct. As a result, the country should preserve traditional Malaysian games to maintain their popularity for centuries to come because playing traditional games will teach our children about culture while also entertaining.

Table 1. Example of Malaysian Traditional Games

\begin{tabular}{llll}
\hline Name & Gender & Player & Tools \\
\hline Gasing & Male & Individual OR Group & Plate-shaped-made of wood \\
Tarik Upih & Male and Female & Group & Pinang tree leaves. \\
Congkak & Male and Female & Group (Two players) & A container with 16 holes that are created with high-quality wood \\
& & and played with rubber seeds. \\
Ketingting & Male and Female & Individual OR Group (2 to 4 players) & Stone \\
Batu Seremban & Male and Female & Individual OR Group & Stone \\
\hline
\end{tabular}

Children enjoy playing, and they spend the majority of their time engaging in a variety of activities. As a result, it is important to provide appropriate toys and games for children to engage in during their spare time. Furthermore, traditional games are more effective than computer games in terms of encouraging physical activity and social interaction skills in children. Children frequently learn new things while engaging in play activities. Children will naturally explore and accumulate experiences through play, and they will always be curious when they try new activities. To achieve this, children are typically active individuals, and it is recommended that they participate in outdoor or indoor activities for at least 120 minutes per week (Kueh et al., 2018). As a result, playing these games will be more enjoyable for the children than playing video games.

\subsection{A Malay Traditional Game: Ketingting}

Ketingting is one of the traditional Malaysian games that include physical activity. This game of Ketingting is also known as Teng Teng or Buat Rumah Batu and is famous among the girls. Girls often played these game compared to boys, probably because these game is not very rugged and required much energy. Ketingting is played by a group of children where there are two to four people inside a court. There is no fixed rule for the number of people in one court. However, the more numbers of players, it will make more difficult for every player to have a goal. Generally, Ketingting's court is made by scraping lines on the ground by drawing the square as a staircase and four wings like an airplane. This is a primary grid for Ketingting (Figure 1).

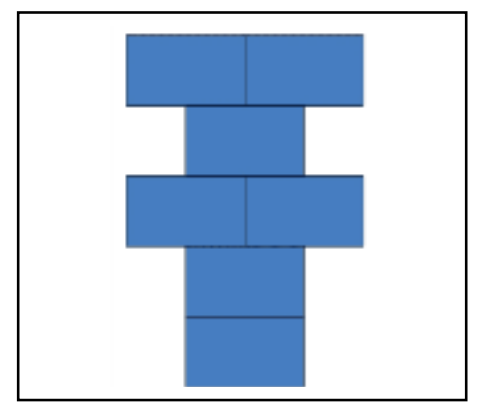

Fig. 1: Traditional Ketingting grid 
At the same time, the end of the square is a semi-circle and is called "Home." Apart from the court, Ketingting has Gundu as an essential tool that plays together. Gundu is a shaped object that can be a stone or anything. Furthermore, players must take turns throwing Gundu in the box number. The player whose throwing stone closest to 'Home' will start the game. Then, the players must jump onto a foot from square to square on the court, requiring muscular endurance and even high patience (Figure 2).

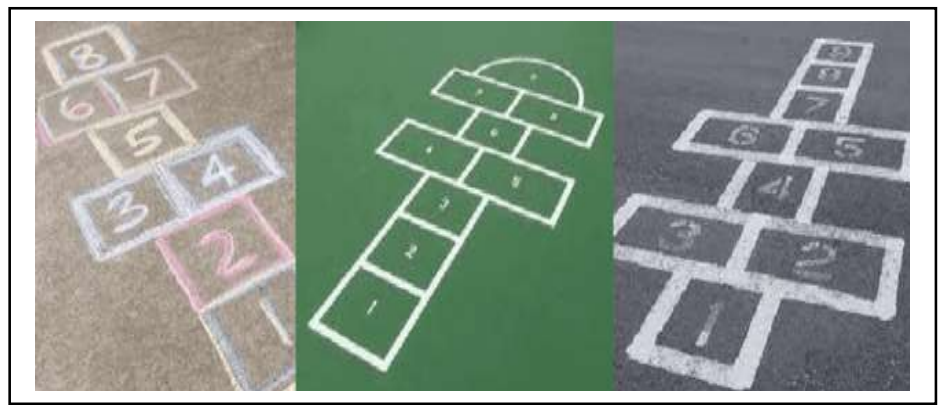

Fig. 2: Traditional Ketingting games court design

\subsection{Research Methodology}

This mixed-method research started the first phase of the research process with a contextual document review to generate ideas from secondary data on journals, reports, and related websites. Then, all those related information on traditional games were collected and further, a systematic analysis was conducted within the collections. Subsequently, the semi-structured interview with 30 parents was conducted as a primary data collection and a questionnaires survey by purposive sampling on public participants. The selection of the parents is based on the volunteer of the public. As the target of the traditional games is for children, and these games can play as an indoor activity, the interview questions contained design elements and material, where the participants answered based on their opinion and understanding. The usage of the mixed method in this study is purposeful mixing of methods in data collection, data analysis, and interpretation of the evidence. The meaning of mixed as an essential step in the mixed methods approach is data linkage, or integration at an appropriate stage in the research process (Ivankova et al., 2006). Figure 3 below shows the research design process employed for this study.

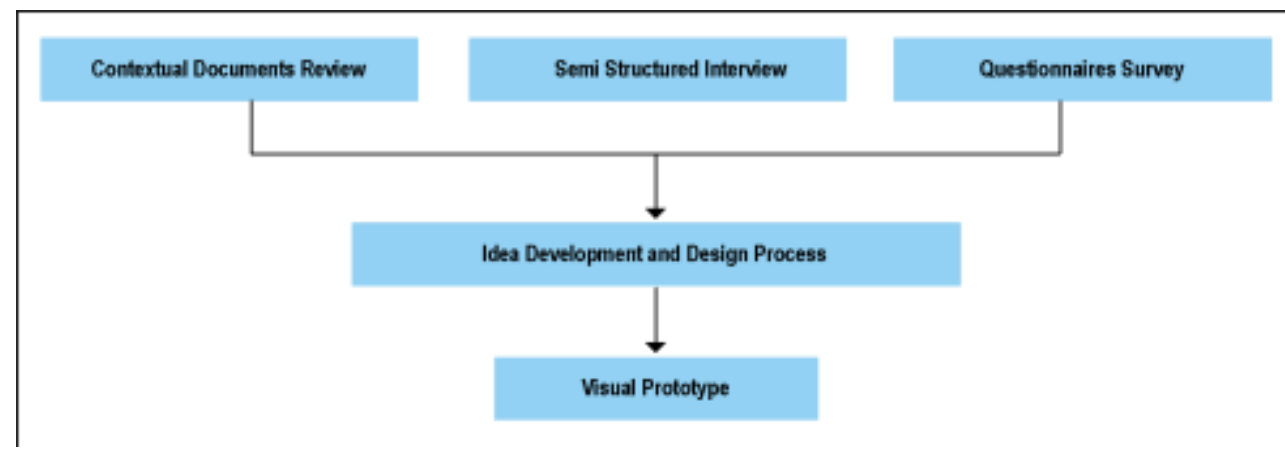

Fig. 3: The research design process

Based on both primary and secondary data gathered, all the data were compared and analyzed thoroughly before designing a new attractive traditional game. The outcomes from each method used are systematically be triangulated as those relevant data contributing to the further development of new attractive traditional games. Finally, the prototype of the new attractive traditional games is proposed to the parents.

\subsection{Selected traditional games for the study}

For this study, a traditional Ketingting game was chosen as a sample of the study. The selection is based on the questionnaire survey by purposive sampling conducted with public participants. The feedback received from the participants established that most of the public is less familiar with The traditional Ketingting game.

\subsection{Findings}

The study revealed a few interesting outcomes from the different methods used and it is presented in the following:

\subsection{Respondents' Demographics}

Findings in this section are all related to respondents' demographics, such as gender and age. The data was collected from survey questionnaires in which all participants were required to fill in their names and age in the survey form. 
Table 2. Respondents' gender

\begin{tabular}{ccc}
\hline Gender & Frequency & Percentage $\%$ \\
\hline MALE & 14 & $48 \%$ \\
FEMALE & 16 & $52 \%$ \\
TOTAL & 30 & $100 \%$ \\
\hline
\end{tabular}

Table 2 shows that of 30 respondents, half of the respondents who answered the questionnaire were female, reporting 16 of them (52\%), while the other half of the respondents were male, reporting 14 of them $(48 \%)$.

\subsection{Respondents' knowledge, familiarity, and awareness of Malaysian traditional children's games}

The outcomes from the questionnaire survey were related to the public knowledge, familiarity, and awareness level of Malaysian traditional children's games, such as have they ever heard about and played any Malaysian traditional children's games before? Have you ever played any Malaysian traditional children's games before? Can you name some of the Malaysian traditional children's games?

The interview has shown that most of the respondents had heard about Malaysian traditional children's games (Table 3). The result reporting 23 of the participants (75\%) said YES while the rest of the respondents had never heard about Malaysian traditional children's games, which 7 of them said NO (25\%). These responses established that most of them have an excellent familiarity level with Malaysian traditional children's games.

Table 3. Respondents' knowledge of Malaysian traditional children's games

\begin{tabular}{ccc}
\hline Question: Have you ever heard about Malaysian traditional & Frequency & Percentage $\%$ \\
children's games before? & & \\
\hline YES & 23 & $75 \%$ \\
NO & 7 & $25 \%$ \\
TOTAL & 30 & $100 \%$ \\
\hline
\end{tabular}

Regarding the public understanding of Malaysian traditional children's games, the outcomes from the survey established that more than half of the public participating in this study had previously played Malaysian traditional children's games during their childhood time. As presented in Table 4 below, it was verified that 19 of the participants (66\%) choose YES, and 11 of them (34\%) who choose NO had never played any Malaysian traditional children's games. Thus this verified that most Malaysian public had a good understanding of Malaysian traditional children's games.

Table 4. Respondents' understanding of Malaysian traditional children's games

\begin{tabular}{lccc}
\hline $\begin{array}{l}\text { Question: Have you ever played any Malaysian traditional children's } \\
\text { games before? }\end{array}$ & Frequency & Percentage \% \\
\hline YES & 19 & $66 \%$ \\
NO & 11 & $34 \%$ \\
TOTAL & 30 & $100 \%$ \\
\hline
\end{tabular}

The survey also ascertained the level of familiarity among the Malaysian public towards the Malaysian traditional children's games. Referring to Table 5,16 of the respondents $(61 \%)$ chose. YES, which could name some of the Malaysian traditional children's games. On the other hand, another 13 of them (39\%) could not name some of the Malaysian traditional children's games where they choose NO. These results prove that most of the Malaysian public is well-known for the Malaysian traditional children's games.

Table 5. Respondents' familiarity with Malaysian traditional children's games

\begin{tabular}{|c|c|c|}
\hline $\begin{array}{l}\text { Question: Can you name some of the Malaysian traditional } \\
\text { children's games }\end{array}$ & Frequency & Percentage $\%$ \\
\hline YES & 16 & $61 \%$ \\
\hline NO & 13 & $39 \%$ \\
\hline TOTAL & 30 & $100 \%$ \\
\hline
\end{tabular}

The survey revealed the participants' understanding and familiarity, but the participants' responses also established the level of awareness. As illustrated in Table 6, most of the research respondents (22 participants) had acknowledged Congkak as the most recognized Malaysian traditional children's game (75\%). However, the result also confirmed that Ketingting is the most undistinguished Malaysian traditional children's game by the respondents. In particular, only 10 participants chose Ketingting compared to 19 participants who chose Batu Seremban, and 17 participants chose Gasing.

Table 6. Respondent's awareness of Malaysian traditional children's games

\begin{tabular}{lcc}
\hline $\begin{array}{l}\text { Question: Which of the Malaysian traditional children's games that you } \\
\text { must recognize }\end{array}$ & Frequency & Percentage \% \\
\hline CONGKAK & 22 & $75 \%$
\end{tabular}




\begin{tabular}{ccc} 
KETINGTING & 10 & $30 \%$ \\
BATU SEREMBAN & 19 & $66 \%$ \\
GASING & 17 & $60 \%$ \\
TOTAL & $\mathbf{3 0}$ & $\mathbf{1 0 0 \%}$ \\
\hline
\end{tabular}

Based on the whole survey results, it can be summary that most of the Malaysian public had a good level of knowledge, familiarity, and awareness towards the Malaysian traditional children's games. Therefore, the results have also clarified that the most prominent game is Ketingting compared to Malaysia's other Malaysian traditional children's games. Thus based on this data, a new attractive proposal for the Ketingting needs to be developed to encourage young children to play traditional games as an indoor activity.

\subsection{The development of the new interface design for the Ketingting games}

In order to develop a new look at the Ketingting games, an interview session with the selected parents was conducted with some procedures. First, the parents were selected based on their familiarity and knowledge of the Ketingting games. Then, they were asked a few questions, including the size of Ketingting, a step of playing Ketingting, color preferences, and themes. The responses gained from them were highly used as a guideline for the development of new Ketingting games.

The development process of the new looks for the Ketingting games begins with measuring the most suitable size for children, based on the information provided by parents through interviews and the information obtained from the review of relevant contextual documents. As a result, a few sketches were created based on the information gathered during an interview session. The concept and idea for the design development are extremely important for the final product's new interface design, which will be based on this concept. Furthermore, the matt material was chosen based on the recommendations made by the parents during the interview session. Five potential designs were created and will be distributed to the parents who took part in the interview. The design was created following design elements that had been established through research in the literature. As an illustration, the colors used should be vibrant and colorful because children can be stimulated to create, strengthen their imagination, be inspired, and have an impact on their aesthetic and motor skills (Anggi, 2020) element used in the design is based on the most well-known icon among young people today.

The parents chose three concepts designed from the evaluation process: jungle, ocean, and galaxy space theme, as shown in Figure 4.

Fig. 4: Concepts design chosen by parents

Further, these three concepts of design were transferred into the technical drawing (Figure 5). At this stage, the design elements' detailing were handled gently, and appropriate colors were chosen accordingly.

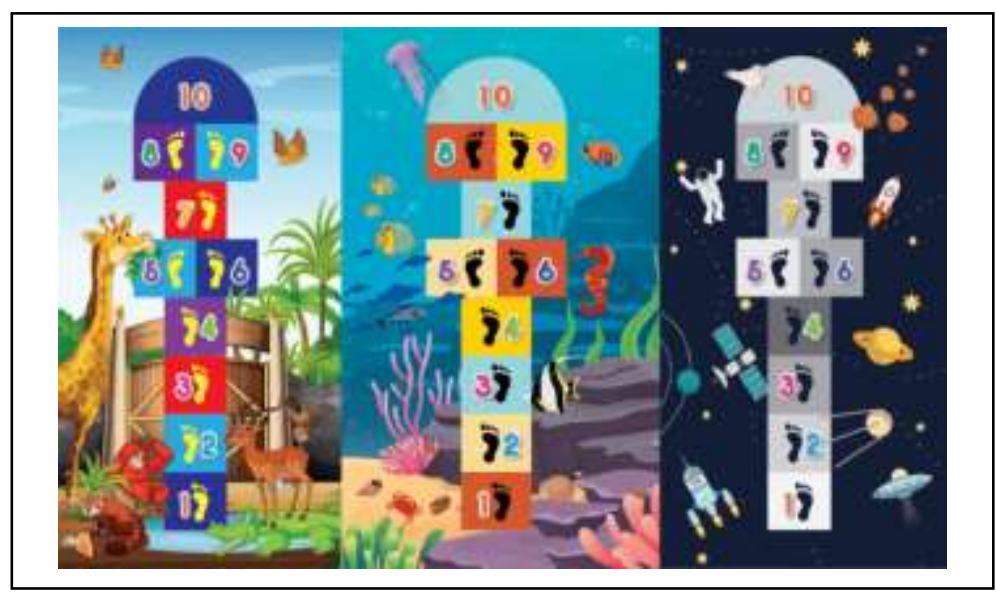

Fig. 5: Three Final Design as Jungle, Ocean, and Galaxy theme 
The shape of the Ketingting is maintained by using a square shape. The overall size for the matt is $2.5(\mathrm{~W}) \times 12(\mathrm{H})$ feet, and each shape is $1 \times 1$ feet, suitable for children to jump from one box shape to another. Figure 6 shows the prototype of new interfaces for Ketingting.

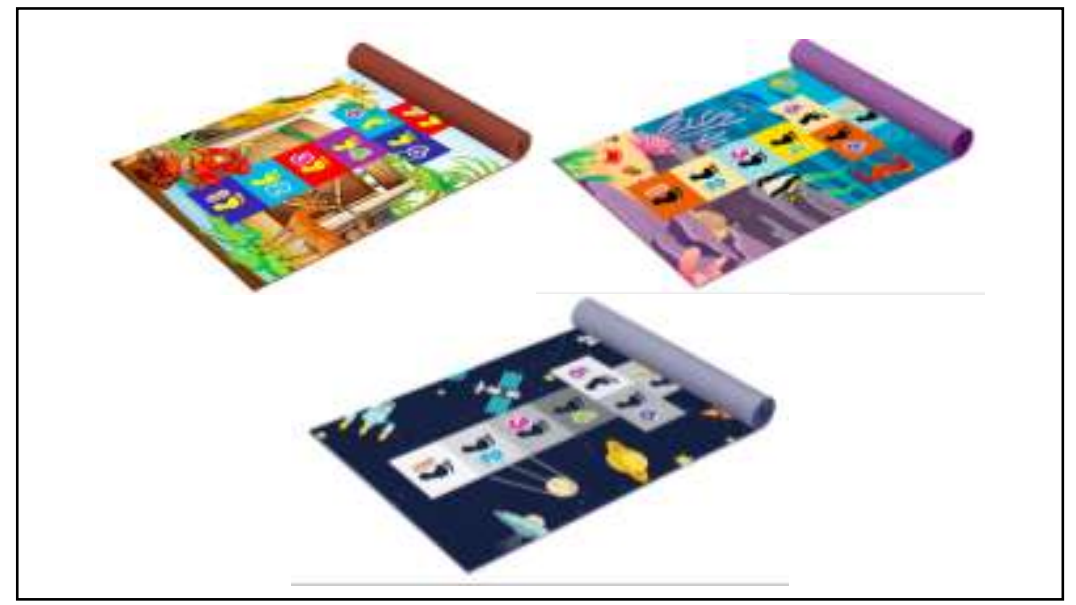

Fig. 6: Sample Prototype on Proposed Material and Interface Design

\subsection{Discussion}

Malaysian traditional children's games have been around for generations. There is plenty of research about the values of preserving, promoting, and playing traditional children's games, but there is very little research about how we can effectively relive Malaysian traditional children's games and pass them on to the next generation. Hence, this project aims to expand the Malaysian traditional children's games to children and the general public so that the outcomes revealed from this study will be highly beneficial to all Malaysian peoples.

Throughout data gathered from the study, a few interesting findings were determined from this study. In particular, the previous literature established that traditional games are more effective than computer games in encouraging physical activity and social interaction skills in children. Towards this claim, it also determined that most of the studies on traditional Malaysian games conducted were not focused on the looks and felt of the game. In contrast, this study revealed that most of the public had moderate knowledge, familiarity, and understanding of the traditional Malaysian games, and not all traditional Malaysian games were recognized well. Thus this study closed that gap by proposing a new Ketingting game with a new interactive interface design that is developed with detailed design elements preferred by the public.

Furthermore, it was verified traditionally that most of the traditional Malaysian games are frequently associated with culture and involve physical activity, while others require the use of critical thinking and strategy. Moreover, past literature also explained that traditional Malaysian games do not have any theme. Interestingly, the interview and questionnaires survey with parents were discovered that theme is one of the important items that need to be considered for the new approach and appearance for any traditional games.

For example, this study proposed three main themes, namely jungle, ocean, and galaxy space, for the new looks of Ketingting, as the target users of the Ketingting game are children (young generation) who are now playing online games that have themes. As children will naturally explore and accumulate experiences through play, providing a new Ketingting game with choices of themes will encourage children's will always be curious when they try a new activity.

Previously, most Malaysian are played the Ketingting game just on the ground at their house. As nowadays most of us are preferred staying at home, this was affected the current lifestyle of most people. However, the World Health Organization recommended that children from 5 to 17 years old should have at least 60 minutes of physical activity every day. In which the longer time of the physical activity, the more positive impact will exist. Consequently, the survey result clearly established that most participants agree to have a new Ketingting game that can be played in their own space and allows them to bring it anywhere easily or can be as a souvenir for other relatives and friends. Thus a new proposed of Ketingting suggested a matt to be based material for a new Ketingting game. With the matt, most parents can easily bring it to picnic or while having outdoor activity together at the park. On top of that, a new proposed Ketingting game can also be helping parents shape the character values, such as physical health, thinking skills, interpersonal and social skills.

Traditional children's games are also valuable assets, and it is important for us to learn, share and transmit. So as to be explained across literature that traditional games are a cultural heritage item, the established results from this study also significantly impacted and supported the previous research. In which, Ketingting is recognized as one of the traditional Malaysian games that are not highly admired by the public even though the game of Ketingting is famous for physical activity that a group of children often plays compared to other traditional games. Thus a new proposed Ketingting easily exposes the children to traditional games and enhances public awareness of Traditional games. In other words, it is important to get people to enjoy traditional children's games because when people enjoy them, they want to learn and understand more about them. 


\subsection{Conclusion \& Recommendations}

Malaysian traditional children's games are a priceless heritage of Malaysia. It symbolizes the nation's customs, culture, and identity, and it needs to be preserved from one generation to the next generation. Within these scenarios, there are a number of studies about Malaysian traditional children's games conducted previously, but how we can effectively preserve, prevent and recreate Malaysian traditional children's games and pass them on to the next generation is still being studied.

This study aimed to propose a new interface design for the Ketingting games that are visually appealing and encourages children to participate in traditional games as an indoor activity. The objective was absolutely achieved throughout the new looks of the proposed Ketingting games. On top of that, traditional games that have been innovated are not meant to change how they have been played or even change the culture. It has been revamped so that the children generation, who are already exposed to the digital era, can be drawn to the innovative work games with vibrant colors and design.

The finding of this study also found out that Indoor Ketinting is expected to be a parent-friendly game for kids that combines new elements with a past shared culture. New elements referred to the design and material used itself. Meanwhile, the parents believe the game is considered a safe run in the house because their children's movements can be supervised while managing their works. At the same time, the culture of playing with family and friends can revive communication skills and interact with one another. Future research should be conducted in determining the effectiveness of the new look and style of playing the Ketingting game among the public.

\section{References}

Abdullah, A. S. (2018). Permainan tradisional jangan dilupakan. Sinar Harian. https://www.sinarharian.com.my/article/3740/EDISI/Pahang/Permainan-tradisional-\%20jangandilupakan

Adnan, M., Shaharudin, S., Abd Rahim, B. H., \& Ismail, S. M. (2020). Quantification of physical activity of Malaysian traditional games for school-based intervention among primary school children. Journal of Taibah University Medical Sciences, 15(6), 486-494. https://doi.org/10.1016/j.jtumed.2020.09.006

Anggi. (2020). Tinjauan Komposisi Warna Ruang Kelas Terhadap Minat Belajar Anak (Studi Khasus Taman Kanak-Kanak Tangerang). Imaginarium, 1(2), 121-136. https://jurnal.bannapati.or.id/index.php//maginarium/article/view/8

Ivankova, N. V., Creswell, J. W., \& Stick, S. L. (2006). Using Mixed-Methods Sequential Explanatory Design: From Theory to Practice. Field Methods, 18(1), 3-20. https://doi.org/10.1177/1525822x05282260

Kueh, Y. C., Abdullah, N., Kuan, G., Morris, T., \& Naing, N. N. (2018). Testing Measurement and Factor Structure Invariance of the Physical Activity and Leisure Motivation Scale for Youth Across Gender. Frontiers in Psychology, 9. https://doi.org/10.3389/fpsyg.2018.01096

Mohd. Salleh Aman. (2006). Asas Pengurusan Sukan. Penerbit Universiti Malaya.

Putra, A., Anuwar, S., Aqma, Z., \& Fahmi, A. (2014). Re-Creation Of Malaysian Traditional Game Namely “Baling Selipar": A Critical Review. https://www.ijset.net/journal/451.pdf

Sahay, S. (2013). Traditional Children's Games of Bihar. Folklore: Electronic Journal of Folklore, 54, 119-136. https://doi.org/10.7592/fejf2013.54.sahay

Sulistyaningtyas, R. E., \& Fauziah, P. Y. (2019). The Implementation of Traditional Games for Early Childhood Education. Proceedings of the 3rd International Conference on Current Issues in Education (ICCIE 2018). https://doi.org/10.2991/iccie-18.2019.75 